\title{
ON THE COMPOSITION OF UNFERMENTED WINES OF COMMERCE.
}

By J. Carter Bell.

Read before the Society of Public Analysts, on 14th Jan., $1 \delta 80$.

Lately I have had some of these so-called wines to examine, which were alleged to be manufactured from the pure juice of the grape. My opinion is, and I think it will be shared by those who study the following analyses, that the juice of the grape is totally absent. These samples of wine have been made the subject of legal proceedings, and the defendants on cross-examination stated that they were made from sugar, crystallised tartaric acid, salycylic acid, and one-sixth of grape juice.

No. 1 bottle was labelled: "Unfermented Port Wine, manufactured from the juice of the grape, for family and sacramental purposes."

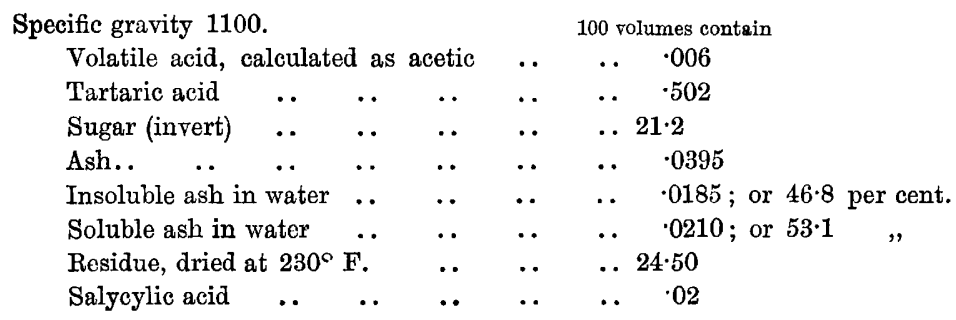

The ash contained traces of chlorine, sulphuric acid, phosphoric acid and potash.

No. 2 bottle was labelled: "Unfermented Wine, Sherry, manufactured from the juice of the grape, for family and sacramental purposes."

Specific gravity 1098.

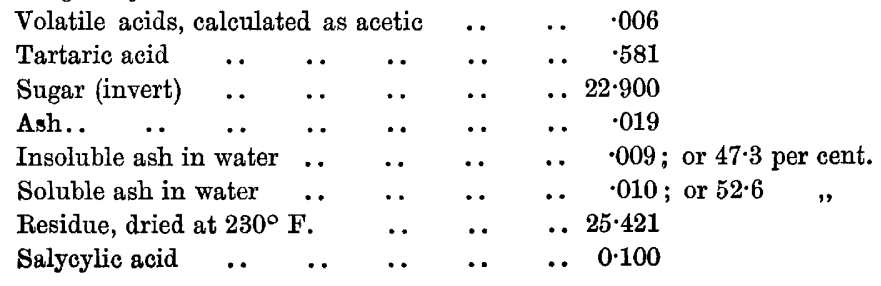


This ash also contained traces of sulphuric acid, phosphoric acid, potash and soda.

No. 3 bottle was labelled: "Unfermented Juice of the Vine, pure uncoloured virgin fruit of the vine, nutriment of the grape without the irritant, for sacramental and dietetic purposes, and in all cases where wine is generally used. This alone should be used where any wine is required."

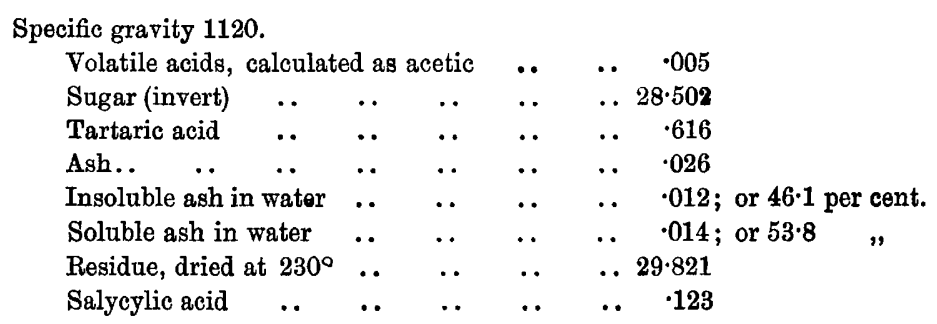

The price charged for these liquors was $2 \mathrm{~s} .6 \mathrm{~d}$. a bottle. I reported that they were merely solutions of sugar and tartaric acid, flavoured and coloured, and kept from fermenting by the addition of a little salycylic acid. I have made a partial analysis of the juice from black and white grapes to compare with the above.

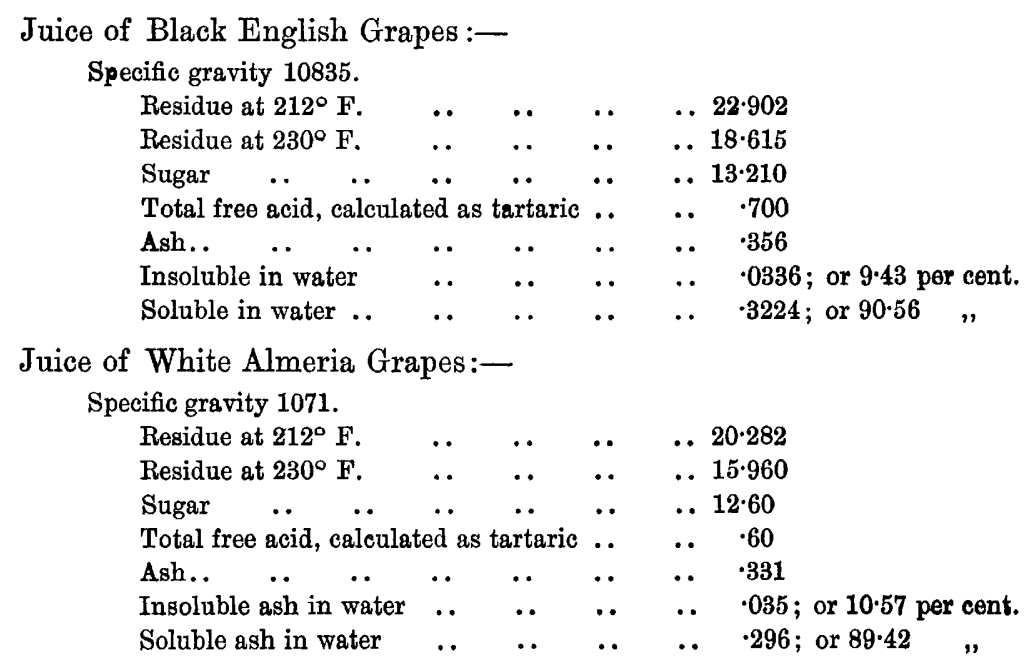

I think it is very evident that one-sixth of grape juice is not in the so-called wines, for it would have raised the percentage of ash, and also have increased the percentage of solubility.

Mr. Heisch expressed his surprise that the case was taken into court. He could not understand what the nature and quality of an unfermented wine should be. In ancient time the juice of the grape was certainly looked upon as wine, but its keeping qualities were doubtful.

Mr. Allen thought it was clearly the purchaser's duty to take the matter into court. There was always some confusion in the English language between wine and vine, but if they called it unfermented wine it certainly represented that it was made from the vine.

Dr. Dupré regretted that such a case should have been brought into court. He himself was consulted by someone who wanted to institute a prosecution; he examined 
some wine, and substantially agreed with Mr. Bell's analysis. His sample was almost free from potash, he could not detect any with the spectroscope, consequently it was not juice of the grape; but then came the question-Was it manufactured from the juice of the grape? Was it cane sugar inverted by the use of tartaric acid? It was impossible to say whether invert sugar was cane sugar inverted, or whether it was grape. In the second place, the tartaric acid was undoubtedly derived from the grape. The chemist cannot say that it is not a sugar of the grape; he has to admit that tartaric acid comes from the grape, and for that reason he (Dr. Dupré) declined to have anything to do with the case. He could not possibly prove that it was not the juice of the grape, although it was obviously an imposture. 